\title{
Conhecimentos sobre varicela de alunos ingressantes em cursos da área de saúde na Universidade Estadual de Londrina e verificação da presença de cicatrizes da doença
}

\section{Knowledge about varicella by first year healthcare students in State University of Londrina and verification of the presence of varicella scars in the students}

\author{
Hellen Yumi Yamaguti ${ }^{1}$; André Clériston José dos Santos ${ }^{2}$; Gerson Zanetta de Lima ${ }^{3}$
}

\section{Resumo}

\begin{abstract}
Varicela é doença infecto-contagiosa causada pelo vírus Varicela-Zoster (VVZ). A varicela em ambiente hospitalar preocupa pelo risco de contaminação de susceptíveis, entre os quais os imunodeprimidos, em quem a doença pode ser grave e letal. Buscamos avaliar os conhecimentos e a evidência clínica de infecção anterior pelo VVZ em estudantes ingressantes em cursos da área de saúde da UEL, em 2004. Investigamos os conhecimentos a respeito do assunto, história anterior da doença, cicatrizes sugestivas de varicela e história vacinal anterior, por meio de questionário e exame da face dos alunos. Encontramos $30 \%$ de indivíduos que não tinham história da doença, vacinação prévia ou cicatriz facial. $56(30,1 \%)$ alunos apresentavam cicatrizes, sendo $44(23,7 \%)$ sugestivas e $12(6,4 \%)$ duvidosas. Verificamos que o número de possíveis susceptíveis no presente trabalho é maior que o citado na literatura.
\end{abstract}

Palavras-chave: Vacinas. Varicela. Universitários.

\begin{abstract}
Varicella is a highly contagious infectious disease caused by a Varicella Zoster virus (VZV). The presence of varicella in the hospital environment is a matter of great concern due to the risk of contamination of susceptible organisms such as immune depressed hosts, in which the disease can be severe and lethal. We assessed the knowledge and clinical evidence of prior infection by VZV in first year Healthcare students from UEL. A questionnaire was used to check the students' knowledge about the disease and its history. Students' faces were examined for the presence of suggestive scars . Results showed that $30 \%$ of students were possibly susceptible to VZV. They did not present history of disease, scars or previous vaccination record against VZV. Scars were present in 56 students $(30.1 \%), 44(23.7 \%)$ were suggestive scars, and $12(6.4 \%)$ dubious. We concluded that the number of possible susceptible cases in our study is higher than those reported in the literature.
\end{abstract}

Key words: Vaccines, Varicella, Health Care Students.

Acadêmica do curso de Medicina da Universidade Estadual de Londrina. Bolsista IC- UEL. Tel.: (043) 33423409.

Acadêmico do curso de Medicina da Universidade Estadual de Londrina

Professor adjunto do curso de Medicina da Universidade Estadual de Londrina

Semina: Ciências Biológicas e da Saúde, Londrina, v. 29, n. 1, p. 3-8, jan./jun. 2008 


\section{Introdução}

A varicela ou catapora é uma doença infecciosa, altamente contagiosa, causada pelo vírus Varicela Zoster (VVZ). Há apenas um sorotipo e o homem é o único hospedeiro natural. Acomete predominantemente crianças, com quadro geralmente benigno. Adolescentes e adultos pode apresentar maior gravidade, com sintomas constitucionais mais intensos e aumento na freqüência de complicações, tais como encefalite e pneumonia. Em gestantes, pode haver transmissão vertical, com risco de abortamento, teratogênese e varicela grave no recém nascido. Em indivíduos imunocompetentes, as complicações são raras e benignas, mas podem ser graves e letais em imunodeprimidos, sobretudo em doentes com leucemia, linfoma ou imunossupressão terapêutica (SADO, 1991; MEDEIROS; MARINO, 2000).

A transmissão do vírus ocorre usualmente por via aérea, desde um a dois dias antes da erupção cutânea, até o desaparecimento das vesículas, no quinto ou sexto dia do período exantemático (SADO, 1991).

A erupção é peculiar e permite o diagnóstico clínico seguro. As lesões evoluem de mácula para pápula, vesícula e crosta rapidamente, são visíveis em vários estágios de desenvolvimento e a distribuição é centrípeta, predominando na cabeça, no couro cabeludo, no tronco e nas raízes dos membros. Pode acometer mucosas. O prurido facilita infecções secundárias, tais como o impetigo, os furúnculos, os abscessos, a erisipela e a celulite, o que pode ocasionar cicatrizes permanentes (STRAUS; SCHMADER; OSMAN, 2003). Estas cicatrizes são classificadas por Jezek, Hardjotanojo e Rangaraj (1981) como em três tipos: circulares e deprimidas, com $2 \mathrm{~mm}$ de diâmetro ou mais; circulares e não deprimidas, neste caso hiper ou hipopigmentadas. Para este estudo, consideramos como cicatriz sugestiva de varicela, como exemplificado na figura 1 .

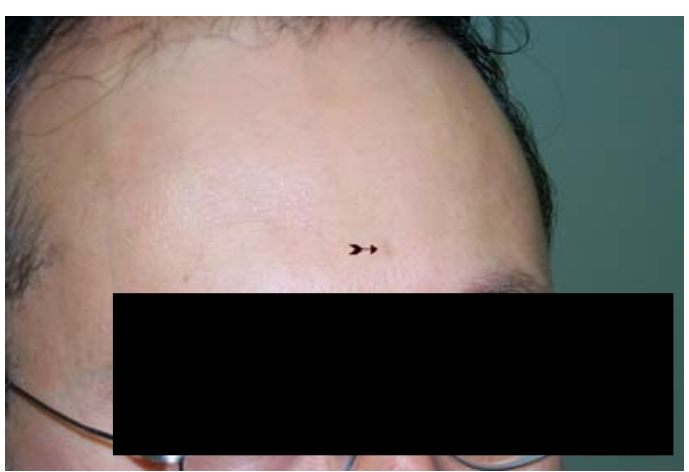

Figura 1. Cicatriz sugestiva de varicela. Foto dos autores.

A doença é endêmica em todo o mundo e é mais comum em áreas de grande concentração populacional; há aumento de incidência a cada 2 ou 3 anos com pico na primavera em zonas temperadas (WHARTON, 1996).

Antes da introdução da vacina de vírus vivos atenuados, em 1995, aproximadamente 4 milhões de casos ocorriam anualmente nos Estados Unidos, com aproximadamente 11.000 hospitalizações e 100 mortes, devidas a encefalites, pneumonias, infecções

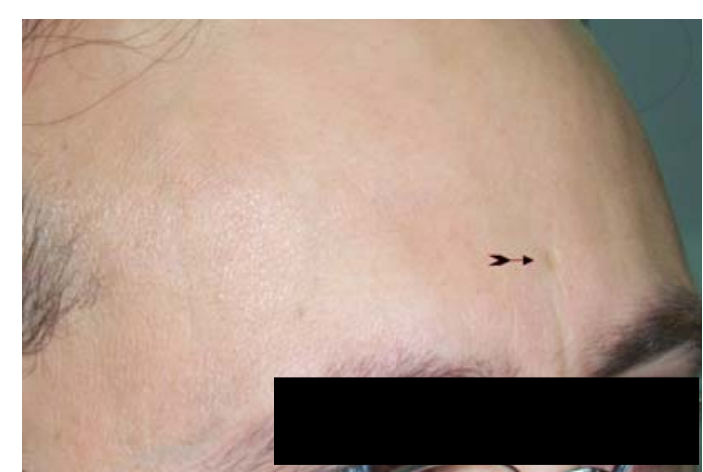

bacterianas secundárias e Síndrome de Reye (MEYER et al., 2000). Os dados epidemiológicos internacionais indicam uma incidência anual de 80 a 90 milhões de casos no mundo. Em crianças saudáveis entre 1 e 14 anos, a letalidade é estimada em 2 mortes por 100.000 casos (CDC 2003a; CDC 2003b). O índice de ataque secundário é de $88 \%$, sendo uma das doenças mais contagiosas que se conhece (WHARTON, 1996). No Brasil, a varicela não é doença de notificação compulsória e os estudos de prevalência, mortalidade e letalidade são limitados. 
Atransmissão de varicela em serviços de saúde foi descrita em diversas ocasiões, atingindo pacientes, visitantes, profissionais de saúde e comunicantes domiciliares dos envolvidos (CDC, 1997). Os profissionais de saúde constituem um grupo peculiar, que deve ter conhecimento adequado da doença, pois ela pode tornar-se fonte de contágio, com grande risco para pacientes imunodeprimidos (SHEHAB; BRUNELL, 1984). Segundo Ribeiro (2002), o início de atividades extracurriculares entre estudantes da área de saúde é precoce no Brasil, geralmente sem treinamento prévio em biossegurança ou verificação da situação vacinal.

Devido aos custos dos métodos soroepidemiológicos, o CDC (1997) e o Ministério da Saúde do Brasil (BRASIL, 2001) recomendam o uso da história anterior da doença como método suficiente de identificação de susceptíveis para fins de vacinação.

O presente trabalho objetiva: (1) avaliar o conhecimento da varicela pelos estudantes ingressantes em cursos da área de saúde da Universidade Estadual de Londrina (UEL); (2) determinar sua susceptibilidade à doença através da história prévia da infecção, da presença de cicatrizes sugestivas e de antecedentes de vacinação.

\section{Casuística, material e métodos}

Após a obtenção de consentimento esclarecido, aplicou-se um questionário com questões sobre história de varicela anterior, vacinação prévia e conhecimentos das características da doença e suas complicações aos estudantes matriculados em 2004 no primeiro ano dos cursos de Medicina, Enfermagem e Fisioterapia da UEL. Os que responderam ao questionário foram submetidos a exame dermatológico da face, para detecção de cicatrizes sugestivas de varicela, tal como descrito por Jezek, Hardjotanojo e Rangaraj (1981). Os dados obtidos foram analisados com o programa EpiInfo 6.04D (CDC/WHO, 2001).

\section{Resultados e discussão}

Dos 197 alunos matriculados, participaram do estudo 186: 72 (38,7\%) de medicina, $55(29,6 \%)$ de enfermagem e $59(31,7 \%)$ de fisioterapia. Houve 11 perdas: seis por recusa, um por abandono do curso e quatro por não terem sido encontrados em duas tentativas.

As idades variaram entre 17 e 37 anos, em média de 20,2 anos; 73,1\% (136) eram do sexo feminino.

Informaram história de varicela anterior 122 $(65,6 \%)$, não tiveram a doença ou não souberam informar 64 (34,4\%). Informaram vacinação prévia $41(22,0 \%)$, negaram $42(22,6 \%)$ e não souberam informar $103(55,4 \%)$. Referiram contato prévio com a doença $116(62,4 \%)$. Ao exame facial, 56 $(30,1 \%)$ apresentavam cicatrizes, sendo sugestivas em $44(23,7 \%)$ e duvidosas em 12 (6,4\%). Entre os com cicatrizes sugestivas, 8 não informaram varicela anterior ou não sabiam de história de varicela prévia. As características dessas cicatrizes são apresentadas na tabela 1 .

Tabela 1. Características das cicatrizes faciais segundo critério de tipicidade e tempo de história de varicela anterior, em estudantes ingressantes dos cursos de Medicina, Fisioterapia e Enfermagem da Universidade Estadual de Londrina, no ano de 2004.

\begin{tabular}{lccccc}
\hline $\begin{array}{l}\text { Tipicidade das } \\
\text { cicatrizes }\end{array}$ & Sim, nos últimos 5 anos & Sim, há mais de 5 anos & Não & Ignora & Total \\
\hline Atípicas & 4 & 7 & 0 & 1 & 12 \\
Sugestivas & 11 & 25 & 5 & 3 & 44 \\
\hline Total & 15 & 32 & 5 & 4 & 56 \\
\hline
\end{tabular}

Semina: Ciências Biológicas e da Saúde, Londrina, v. 29, n. 1, p. 3-8, jan./jun. 2008 
Jezek, Hardjotanojo e Rangaraj (1981) encontraram cicatrizes circulares e deprimidas em $18,4 \%$ de indivíduos somalis que haviam apresentado varicela, confirmada por exame de crostas por microscopia eletrônica para detecção de partículas virais. Segundo os autores, essas lesões eram indistinguíveis das causadas por varíola minor, embora em muito menor número. Apenas $2,4 \%$ dos indivíduos apresentavam mais de 4 lesões cicatriciais. Apontam ainda que as cicatrizes foram mais comuns na faixa etária de 20 a 29 anos em relação aos mais jovens. Leung, Kao e Sauve (2001) encontraram cicatrizes em $18,7 \%$ das crianças entre 2 e 14 anos que haviam apresentado varicela até um ano antes da pesquisa por eles conduzida em Calgary, Canadá. Estas cicatrizes se distribuíam por todo o corpo, e delas $40,8 \%$ ocorriam na face, o que corresponde a $7,6 \%$ do total de crianças estudadas. Fatores ambientais e epidemiológicos podem resultar em variações entre populações tanto na incidência da doença quanto das complicações infecciosas que determinam as cicatrizes.

Quanto aos conhecimentos sobre a doença, $134(72,0 \%)$ dos alunos conheciam a etiologia e $17(9,1 \%)$ conheciam todas as características das lesões da varicela. Somente $6(3,2 \%)$ citaram corretamente possíveis complicações. Respostas a outras questões a respeito da doença apresentaram distribuição mais variada e não significativas. Este conhecimento parcial da doença é esperado, devido aos sujeitos serem alunos ingressantes. A maioria dos alunos demonstrou conhecimentos básicos acerca da doença e poderesponder satisfatoriamente a uma campanha de vacinação.

A diferença entre os alunos que negaram/ ignoraram história de varicela $(34,4 \%)$ e os que negaram/ignoraram e não tinham cicatrizes $(30,0 \%)$ foi pequena $(4,6 \%)$. O conhecimento da situação vacinal prévia é necessário para propostas de medidas de controle efetivas, mas é freqüente que os documentos comprobatórios de vacinação individual não sejam apresentados e a adesão da comunidade a inquéritos a respeito de imunidade é baixa (HASEGAWA; LOPES; GUTIERREZ, 2001; FARIA et al., 2001). MacMahon et al. (2004), em estudo realizado na Inglaterra, mostraram que as cicatrizes não aumentam o valor preditivo de uma história positiva para varicela em situações nas quais a soropositividade é maior que $90 \%$.

As recomendações do Programa Nacional de Imunizações destinam-se, em geral, à vacinação de profissionais já formados e que têm contato direto e conhecido com pacientes imunodeprimidos (BRASIL, 2001).

O Comitê Assessor em Práticas de Imunizações dos Estados Unidos (CDC, 1997) recomenda a vacinação de todos os indivíduos maiores de treze anos de idade com passado vacinal negativo ou ignorado, e que freqüentem ambientes onde seja provável a circulação do vírus. A história clínica de ausência de ocorrência prévia da doença para a seleção de candidatos à vacinação (BOLYARD et al., 1998; CDC, 1997), pode ser aceita embora MacMahon et al. (2004) tenham sugerido que um teste sorológico seja necessário na atual situação demográfica e epidemiológica da Inglaterra, onde ocorre um aumento do contingente de populações provenientes de regiões tropicais. Segundo essa autora, para pessoas provenientes de regiões de clima temperado, a história de varicela isolada tem alto valor preditivo positivo, pois a prevalência dos soropositivos entre os adultos é de $94,9 \%$, enquanto apenas $84,4 \%$ dos provenientes de regiões tropicais são soropositivos.

De acordo com Lima, Fernandes e Ramos Júnior (2000), entre médicos residentes no Rio de Janeiro, $22,0 \%$ eram possíveis suscetíveis à varicela pelo critério de história anterior. No presente trabalho, foram identificados $30,0 \%$ de possíveis suscetíveis, sendo os critérios (história anterior, cicatriz sugestiva ou história de vacinação prévia) mais amplos que os de Lima (história anterior).

Um estudo de soroepidemiologia realizado em quatro capitais brasileiras em adultos de 21 a 30 anos (CLEMENS et al., 1999) evidenciou 
apenas $8,0 \%$ de soronegativos para varicela, índice que representa uma diferença grande em relação aos resultados deste trabalho e o de Lima, Fernandes e Ramos Júnior (2000). Se estes valores fossem válidos para a realidade da UEL em 2004, estaríamos vacinando 56 alunos, 51 dos quais desnecessariamente e deixando de vacinar 5 que necessitariam da vacina. Essa diferença sugere a necessidade de realização de testes sorológicos em todos os sujeitos potencialmente susceptíveis, pois a economia em doses de vacinas pode compensar parcialmente os custos desses testes.

\section{Referências}

BOLYARD, E. A.; TABLAN, O. C.; WILLIAMS, W. W.; PEARSON, M. L.; SHAPIRO, C. N.; DEITHMAN, S. D. Guideline for infection control in health care personnel, 1998. American Journal of Infection Control, Saint Louis, v. 26, n. 3, p. 289-354, 1998.

BRASIL. Ministério da Saúde. Fundação Nacional de Saúde. Manual dos Centros de Referência de Imunobiológicos Especiais. 2.ed. Brasília: Ministério da Saúde/FUNASA, 2001.

CENTERS FOR DISEASE CONTROL AND PREVENTION - CDC; WORLD HEALTH ORGANIZATION - WHO. EpiInfo 6.04D: Programa estatístico. Atlanta, 2001. Disponível em: <http://www. cdc.gov/epiinfo/Epi6/EI6dwni.htm>. Acesso em: 01 jul. 2003.

CENTERS FOR DISEASE CONTROL AND PREVENTION - CDC; ADVISORY COMMITTEE ON IMMUNIZATION PRACTICES - ACIP. Immunization of health care workers: Recommendations of the Advisory Committee on Immunization Practices (ACIP) and the Hospital Control Practices Advisory Committee (HICPAC). MMWR: Morbidity and Mortality Weekly Report, Atlanta, v. 469, n. RR-18, p. 1-42, 1997.

Notice to readers: Recommended adult immunizations schedule. United States, 2003-2004. MMWR: Morbidity and Mortality Weekly Report, Atlanta, v. 52, n. 40, p. 965-969, $2003 \mathrm{a}$.

Recommended childhood and adolescent immunizations schedule. MMWR: Morbidity and Mortality Weekly Report, Atlanta, v. 52, n. 4, p. Q1-Q4, 2003b.
CLEMENS, S. A. C.; AZEVEDO, T.; FONSECA, J. C. F.; CAVALCANTI, A. M.; SILVEIRA, T. R.; CLEMENS, S. R. Soroepidemiologia da varicela no Brasil-resultados de um estudo prospectivo transversal. Jornal de Pediatria, Rio de Janeiro, v. 75, n. 6, p. 433-441, 1999.

FARIA, D. S.; PEREIRA, E. M.; LEÃO, F. E. A.; PEDROSO, E. R. P. Prevalência da vacinação entre acadêmicos de Medicina da Universidade Federal de Minas Gerais. Revista da Sociedade Brasileira de Medicina Tropical, Rio de Janeiro, v. 34, supl. 1, p. 444445, 2001.

HASEGAWA, E. M.; LOPES, M. H,; GUTIERREZ, E. B. Avaliação do programa de vacinação para estudantes de medicina. Boletim da Sociedade Brasileira de Imunizações, São Paulo, v. 3, n. 4, p. 4-8, 2001.

JEZEK, Z.; HARDJOTANOJO, W.; RANGARAJ, A. G. Facial scarring after Varicella: a comparison with variola major and variola minor. American Journal of Epidemiology, Baltimore, v. 114, n. 6, p. 798-803, 1981.

LEUNG, A. K. C; KAO, C. P.; SAUVE, R. S. Scarring resulting from chickenpox. Pediatric Dermatology, Boston, v. 18, n. 5, p. 378-380, 2001.

LIMA, L. A. A.; FERNANDES, G. C.; RAMOS JÚNIOR, A. N. Inquérito vacinal entre médicos recém formados possível susceptibilidade a doenças imunopreviníveis. Revista da Sociedade Brasileira de Medicina Tropical, Rio de Janeiro, v. 33, supl. 1, p. 302-303, 2000.

MACMAHON, E.; BROWN, L. J.; BEXLEY, S.; SNASHALL, D. C.; PATEL, D. Identification of potential candidates for Varicella vaccination by history: questionnaire and seroprevalence study. British Medical Journal, v. 329, n.7465, p. 551-552, 2004.

MEDEIROS, E. A. S.; MARINO, C. G. G. Imunização em profissionais de saúde. In: FARHAT, C. K.; CARVALHO, E. S.; WECKX, L. Y.; CARVALHO, L. H. F. R.; SUCCI, R. C. M. Imunizações: Fundamentos e Prática. 4.ed. São Paulo: Atheneu, 2000. p 239-248.

MEYER, P. A.; SEWARD; J. F., JUMAAN, A. O.; WHARTON, M. Varicella mortality: trends before vaccine licensure in the U.S., 1970-1994. Journal of Infectious Diseases, Chicago, v. 182, n. 2, p. 383-390, 2000.

RIBEIRO, J. G. L. Necessidade de adoção de uma política especifica de imunização para acadêmicos de medicina: a situação da Faculdade de Ciências Médicas de Minas Gerais. 2002. Dissertação (Mestrado em Medicina) - Faculdade de Medicina da Universidade Federal de Minas Gerais, Belo Horizonte. 
SADO, K. Varicela. In: BALDY, J. L. S.; AMATO NETO, V. Doenças transmissíveis. 3.ed. São Paulo: Sarvier, 1991. p 869-875.

SHEHAB, Z. M.; BRUNELL, P. A. Susceptibility of hospital personnel to varicella-zoster virus. Journal of Infectious Diseases, Chicago, v. 150, n.5, p. 786, 1984.
STRAUS, E. S; SCHMADER, K. E.; OSMAN, M. N. Varicella and Herpes Zoster. In: FREEDBERG, I. M. et al. Fitzpatrick's Dermatology in General Medicine. 6.ed. Philadelphia: McGraw-Hill, 2003. p. 2070-2085.

WHARTON, M. The epidemiology of varicella-zoster virus infections. Infectious disease clinics of North America, Philadelphia, v. 10, n. 3, p. 571-81, 1996. 